\title{
51. The Fœtal Membranes and Placentation of Chiromys
} madagascariensis. By Professor J.P. HiLL, F.R.S., and R.H.Burne, M.A. (With an Appendix on the External Characters of the Fœtus, by R. 1. Pocock, F.R.S.)

[Received October 24, 1922 : Read October 24, 1922.]

$$
\text { (Plates I.-VI.*; Text-figures 1-6.) }
$$

The structure of the foetal membranes and placenta of the Lemurs was first made known during the years $1871-1877$ by the researches of A. Milne Edwards $(\mathbf{1}, 2,3)$ and Sir William Turner $(5,6)$. Contrary to the prevailing belief, the placenta was shown to be of the non-deciduate diffuse type, quite unlike that of the Apes and Man, and more nearly resembling that of certain Ungulates, particularly the Pigs.

The species examined at that time belonged exclusively to the subfamilies Lemurince and Indrisince, of Madagascar, but in 1884 a brief description of the fœtal membranes of the remarkable Madagascar Lemur, Chiromys, was published by Milne Edwards (4), and twenty-five years later Hubrecht (10) reproduced a photograph of the surface of the chorion of a fœtal specimen of the same in the collection of the British Museum and now in our possession (our specimen B).

In 1894 our knowledge, hitherto confined to the Madagascar species of the order, was extended to the Lemurs of the Old World by the preliminary description by Hubrecht (8) of pregnant uteri of Nyciicebus tardigradus and Tarsius spectrum. He showed that in the first-named species the placenta conformed, with some minor though characteristic differences, to that of the Madagascar Lemurs, but that the placenta of Tarsius was quite different, and resembled that of the Apes and Man in being discoidal and deciduate. In a later paper (9) Hubrecht gave a more detailed account of the development of the placenta of T'arsius, but no further description of that of Nycticebus has appeared. In 1902, however, our knowledge of the placentation of the Lorisiformes was further extended by the publication of a lengthy paper by Strahl (14) on the placenta of the African genus Galago, wherein it is shown that Galago, in the details of its placentation, agrees more closely with Nycticebus than with the Madagascar Lemurs, as was to be expected. Strahl in a subsequent paper (15) and more recently Jenkinson (16) have added to our knowledge more especially of the histology of the placenta of these latter forms.

The fotal membranes and placentation have now been described in more or less detail in representatives of all the existing. families and subfamilies of the two groups of the true Lemurs-

* For explanation of the Plates, see p. 1169. 
the Lemuriformes and the Lorisiformes*, and as the outcome, we know that all the true Lemurs are characterized by the possession of the same non-deciduate, diffuse, epithelio-chorial type of placenta, which differs in the two groups and from genus to genus only in comparatively unimportant though apparently quite characteristic details, the general nature of which is indicated in the following paragraphs ( $c f$. also $1 \%)$.

Development is of the central type, and the entire mucosa of the bicornuate uterus is involved in placental formation; for, though development begins in one of the uterine horns, and the fotus, invested in its membranes, later occupies both that and the body of the uterus, the chorionic sac sends a prolongation, at any rate during the later stages of pregnancy (Milne-Edwards, 3 ; Turner, 5 ; Anthony, 12), also into the unoccupied or nonfœtal horn, forming what we shall speak of as the chorionic appendage. The uterine epithelium, immediately below which are richly developed maternal capillaries, persists throughout the gestation period, and is regarded both by Turner (5) and Strahl (14) as being actively secretory. The uterine glands also persist in an active functional condition. They mostly open in groups in localised bare areas in the Lernuriformes (Milne-Edwards, 3; Turner, 5; Strahl, 15), and in Galago among the Lorisiformes (Strahl, 14), or their openings are more evenly distributed at the bottom of the uterine crypts, as in Nycticebus (Hubrecht, 8). The mucosa is always more or less markedly folded, the villous outgrowths of the chorion fitting into the depressions or crypts between the folds.

The chorion is early established as a complete bilaminar membrane enclosing the embryonal formation, and becomes secondarily vascularised by the umbilical (allantoic) vessels as the result of the early fusion of the outer wall of the allantois with its inner surface. The chorion in this way is converted into an allanto-chorion over the greater part of its extent. The allantois is voluminous and multilobulate, covering the greater part of the inner surface of the chorion; and in later stages the amnion is fused with its inner wall, the extra-embryonal cœlom being obliterated. The yolk-sac is early separated off as a complete vesicle, appearing in later stages as a quite small flattened sac (Milne Edwards, 3 \& 4; Strahl, 14).

The chorion, except over certain small restricted areas and at its vaginal extremity, is produced into villous processes, which amongst the Lemuriformes take the form of large laminar or leaf-like folds, secondarily branched, or amongst the Lorisiformes, of nodular processes. They are covered by a simple layer of trophoblast (tropho-ectoderm), below which is a richly developed plexus of allantoic capillaries. These villous outgrowths fit into complementary depressions of the folded surface of the mucosa,

* See our reference list, in which the species studied have been noted under the names of the investigators. 
the placental connection being constituted by the close interdigitation of the vascular villous processes of the fœtal chorion with the vascular folds of the uterine mucosa or maternal decidua. There is no organic continuity between the two, and at birth the villous processes are simply withdrawn from their mucosal pockets, there being apparently no loss of maternal tissue-i.e., the placentation is non-deciduate.

The secretion of the uterine glands is of high importance for the nutrition of the fotus, and in the Lorisiformes there are present pockets or recesses of the chorion (chorionic recesses, Hubrecht, 8; chorionic vesicles, Strahl, 14) specially adapted for its collection and absorption, their openings in G'alago lying opposite the depressed bare areas on which the uterine glands open (Strahl, 14). Corresponding bare areas of the chorion, in contiguity with uterine bare areas, would seem to subserve the same function in the Lemuriformes, though chorionic vesicles of simple structure are, we find, present in Chiromys and seem also to occur in Lemur mongoz (Strahl, 15).

Notwithstanding the extent of our knowledge of the placentation of the Lemurs, and the fact that in essentials the fotal membranes and placenta of Chiromys are similar to those of other Madagascar forms, we offer no apology for presenting yet another contribution to this subject, since the aberrant nature and great rarity of the species make it desirable that these structures should be described and figured more fully than has been done in the papers (4) and (10) referred to above.

The following account is based on the examination of two uteri in a late and almost identical stage of pregnancy. Both fœtuses appear to be near full term, and are practically fully haired with the eyelids open. The external characters of the fotus (Specimen B, Pl. III. fig. 6) are described by $\mathrm{Mr}$. R. I. Pocock in the Appendix to this paper.

Specimen $A$ * was obtained from a female purchased several years ago by the Royal College of Surgeons from Mr. J. Hamlyn. The hinder part of the body was removed, and the uterus preserved in situ in alcohol.

Specimen B was originally in the collection of the British Museum. In 1921 it was received in exchange by one of us (H.) through the kind offices of Mr. Oldfield Thomas. According to the label accompanying the specimen, it was purchased of Mr. Stevens on October 1st, 1864. The uterus which accompanied the specimen was strongly contracted, from which we judge that it had been opened in the fresh state and, after extraction of the foetus enclosed in its membranes, had been with the latter at once plunged into spirit. Apart from the partial separation and disappearance in places of the superficial epithelial layers, the fœtal membranes and uterus prove to be remarkably well preserved. This specimen formed the

* R. Coll. Surg. Museum, Physiol. Series, Nos. 3582.5, 3582.51, 3582.52. 
subject of Hubrecht's brief reference and figure $(10$, p. 115 \& fig. 151).

For comparison with our preparations of Chiromys, we have had available some sections of the placenta of Nycticebus from the collection of the late Dr. R. Assheton, kindly placed at the disposal of one of us by Mrs. Assheton, and also preparations made from the imbedded material of Lepilemur, which formed the subject of the contribution of the late Dr. J. W. Jenkinson (16), for the use of which we are much indebted to Prof. E. S. Goodrich, F.R.S.

\section{UTERUS.}

The uterus (specimen A, Pl. I. fig. 1) is much dilated, and forms a pear-shaped mass about the size and figure of a small clenched fist, continuous with the vagina posteriorly by a short narrow cervical segment. Its convex anterior end projects forward further on the left than on the right, and is indented to the right of the mid-line by a shallow vertical furrow, which marks the division between the two unequally dilated horns. Internally this division is emphasised by the projection of a semi-lunar fold (Pl. I. fig. 1, $f l d$.) from the line of the external furrow for some 2 or $3 \mathrm{~cm}$. into the uterine cavity.

From the side of each horn, a short distance posterior to its fundus, projects a fold of the broad ligament carrying the contorted Fallopian tube, and by its reflexion forming a deep peritoneal pouch, within which lies the ovary attached by a long ovarian ligament to the uterus. About $1 \mathrm{~cm}$. ventral to the termination of the Fallopian tube is the commencement of the round ligament whence the ligament passes to the groin in a fold projecting freely from the surface of the broad ligament.

In specimen $\mathrm{B}$, owing to strong contraction during preservation, it is probable that the shape of the uterus is to some extent unnatural. It is transversely extended, being nearly twice as broad (at the level of the Fallopian tubes) as the distance between its cerviz and fundus. The left horn is considerably more dilated than the right, and forms a rounded bulbous extension of the corpus uteri, with the entry of the Fallopian tube placed some distance behind its anterior margin. The right horn is much smaller with a conical apes to which is attached the Fallopian tube. The union of the two horns is not indicated externally by a furrow as in specimen $\mathrm{A}$, but upon the antero-ventral surface the position of the internal fold that separates them is marked by a slight ridge.

The uterus (specimen A) when opened along its posterior (dorsal) aspect was found to be completely filled both as regards cornua, corpus, and cervix by the fotal membranes (Pl. I. fig. 1), the well-marked chorionic appendage occupying the right cornu, and a prolongation of the main sac extending into the cervical canal (Pl. I. fig. 1, p.). Within them lay the fœetus, far arlvanced 
in development, occupying the left horn and corpus uteri, with its back turned to the right and presenting with the head.

This position of the footus is that generally found in Lemurs towards the end of gestation, though sometimes the fœtus may be in the right horn and corpus uteri (Anthony, 12, p. 247; Turner, 5, p. 574), and sometimes may offer a breech presentation (Turner, 5, p. 573 \& \%, p. 278) or may lie diagonally (Turner, 5, p. 574).

In specimen B, so far as we can judge, the elongate embryonal formation lay disposed transversely in the uterus, with the headend of the fotus in the corpus uteri, directed to the right, its thicker remainder occupying the more extensive left portion of the corpus uteri as well as the left cornu, whilst the chorionic appendage (Pls. III., IV. figs. $5 \& 7$ ) projected in to the right cornu. The mid-region of the back of the fotus would thus lie closely apposed to the internal os uteri, in a position somewhat similar to that occupied by one of 'Turner's specimens of Lemur rufipes (5, p. 574$)$.

The wall of the uterus in specimen A is comparatively thin. Its mucous lining (except within the cervix and around the internal os where it is smooth) is thrown into irregular anastomosing folds with intervening depressions, within which are received the villous folds which project from the chorion. The general correspondence between the mucosal folds and depressions on the one hand and the laminar villous folds and the clefts between them on the other is clearly apparent in Pl. I. fig. 1, and though both sets of folds are somewhat shrunken, there was clear evidence of close interdigitation between the two.

In specimen A, the cervix was occupied, as mentioned above, by a conical smooth prolongation of the chorion, but in specimen $B$ the fotal membranes did not extend beyond the os internum, and the cervix was empty and produced internally into longitudinal folds. The os externum in B projected freely into the vagina and possessed a lobed margin. In A, it was in addition guarded by two semi-lunar folds, projecting from the wall of the vagina, as in the unimpregnated state*. The cervical canal in neither case showed any indication of being closed, as in the human subject, by a plug of secretion.

In specimen $B$, the mucosa reaches its maximum thickness in the right cornu, and its folds are here more markedly developed than elsewhere in the uterus, in correspondence with the strong development of the laminar villi on the chorionic appendage. Round the internal os, as in A, the mucosa is relatively smooth.

A low-power view of a section through the body of the uterus (specimen B) is reproduced in Pl. V. fig. 12. The muscularis (musc.) though thin relatively to the size of the uterus, is well developed, and in sections in the appropriate plane is seen to consist of an outer slightly thicker layer of longitudinal smooth muscle

* R. Coll. Surg. Museum, Physiol. Series, No. 2815 A. 
and an inner thinner layer of circular fibres; between the two layers there are situated the main branches of the uterine vessels. In the muscularis there are present numerous endothelially lined cleft-like lymphatic channels.

In the intervals between its much subdivided folds the mucosa appears as a relatively thin layer, well supplied with vessels. Over much of its surface the uterine epithelium has separated in our material, but in places it is quite well preserved. It consists of a single layer of, for the most part, relatively large and plump cubical cells with active looking oval or spherical nuclei (text-fig. 1), though here and there the cells are narrow columnar or even flattened and plate-like. It varies in thickness from 016 to $\cdot 008 \mathrm{~mm}$. Whilst its free surface tends to be smooth and regular, its deep surface, in the absence of a basement membrane, is wavy and irregular, the basal ends of its cells being directly applied to the walls of the subjacent capillaries which, as Milne Edwards (3) and Turner (5) have shown, form a richly developed subepithelial plexus. Both Turner (5) and Strahl (15) have maintained that the uterine epithelium is actively secretory,

Text-figure 1.

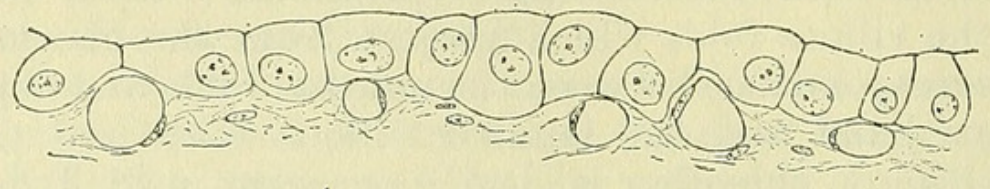

Section uterine epithelium and underlying capillaries.

but of that we have no positive evidence in our material. Lymphoid exudation no doubt plays a considerable rôle in the nutrition of the fotus, and it is quite likely that the uterine epithelium is concerned in its transference to the trophoblast cells.

The uterine glands (Pl. V. fig. 12, ut.gl.) are mainly confined to the basal part of the mucosa, though not infrequently they are found extending far out in the folds. They show a distinct tendency to be arranged in groups separated by regions in which they are sparse or absent, but we have not been able to determine if they open together, on restricted bare areas as described for other Madagascar Lemurs by Milne Edwards (3), Turner (5), and Strahl (15). We have not been able to distinguish such areas in surface examination of the mucosa, and in the sections the glands are seen to open between the bases of the folds by way of ductlike involutions of the uterine epithelium.

The glands are most numerous in the thick mucosa of the right horn, and are for the most part of relatively small diameter (.048-.12 mm.), though some are much thicker (up to $\cdot 35 \mathrm{~mm}$.).

The glands are lined by a single layer of low columnar cells with spherical deeply staining nuclei in their basal halves, and are actively secretory, the secretion appearing in the gland 
lumina as small homogeneous spherules and as a deeply staining coagulum. Where the glands are enlarged and not actively secreting, the lining cells are cubical. In Lepilemur the glands are very similar to those of Chiromys, but we have observed distinct evidence of branching. Jenkinson (16) states that they "open at the base of depressions"; we find that in this species the localised areas on which the glands open may or may not be depressed, and that they are characterised by the marked thickening and folding of the uterine epithelium. These areas are situated opposite specially thickened patches of the chorionic trophoblast, to which we shall later make reference. In Nycticebus the glands are larger than in Chiromys, but are otherwise similar. Hubrecht (8) states that they open on the bottoms of the crypts in which the villi are situated. In Galago they open, according to Strahl (14), partly on depressed bare areas in relation with chorionic vesicles, partly (in the main horn) independently (p.193). Strahl is of opinion that in Galago extravasated blood in the mucosa is taken up by the uterine gland cells, and is utilised for the nutrition of the fœetus. In none of the material we have examined (Chiromys, Lepilemur, Nycticebus) have we seen any trace of extravasated blood in the corium of the mucosa, though the later is richly supplied with vessels.

\section{Feetal Membranes.}

\section{Allanto-chorion.}

The allanto-chorion, or chorion as we may term it for brevity (Pl. I. fig. 1), forms an exact cast of the interior of the uterus, extending from the apex of one horn to the apex of the other, filling the entire corpus uteri and prolonged (in specimen A) by a blunt conical process into the cervix as far as the os externum. Its surface is covered almost all over by characteristic villous outgrowths in the form of more or less broad swollen pleats marked superficially by delicate sinuous convolutions, presenting an appearance as nearly as possible similar to the figure given by Strahl $(15$, pl. 36 . figs. $4 \& 5)$ of the chorion of a $30-\mathrm{mm}$. fœetus of Propithecus. The surface of the folds thus appears to be less elaborated than in the Lemurs described by Turner $(\mathbf{5}$, p. $575 \&$ \%, p. 279) or in the later stages of Propithecus (Strahl, 15, p. 273). The primary pleats are set for the most part transversely to the length of the chorionic sac, becnming. more regularly disposed in each horn in parallel circular wreathlike bands.

In specimen B (Pls. III., IV. figs. 4, 5, \& 7-10), the laminar arrangement is in parts masked to some extent by the depth of the secondary foldings which break up the primary pleats and produce a more lobulated surface than in the specimen A (Pl. IV. fig. 9). This lobulation must not be confused with the appearance presented by the characteristic polygonal villi of the genus Nycticebus 
(Hubrecht, 8, p. 93), nor with that of the somewhat similar villi of Galago (Strahl, 14\& 15 , pl. 38. fig. 17); it is simply a slight elaboration, such as that described by Strahl in the later stages of Propithecus, of the laminar arrangement typical of all the Madagascar species.

In opening the uterus of specimen A, it was observed that the folds and corrugations upon the surface of the chorion fit closely into the corresponding depressions in the uterine mucosa. The connection between the two is, however, relatively slight, and by gentle traction the chorionic sac can be detached from the uterus without rupture of tissue. The degree of cohesion between the two differs in different parts, depending on the size and complieation of the folds and the depth to which they interdigitate with the corresponding irregularities of the uterine mucosa, being greatest in the non-fœtal (right) horn, where the chorionic folds are most pronounced (Pl. I. fig. 1) and least towards the cervix, where they are fewer and less prominent.

Although, as mentioned above, the folds cover most parts of the chorion, there are areas from which they are almost or entirely absent (Pl. I. fig. 1). Such bare places are very illdefined, and although at first sight they suggest the bare patches described by Milne Edwards (3) and Turner (5), and figured by Strahl for Propithecus (15, pl. 37. fig. 14), they can hardly bear a strict comparison with them. In the first place, they are in every way so much less definite and in the second place, they have apparently no uterine counterpart in the form of bare areas of the mucosa.

The position of these relatively bare areas is no more definite than their boundaries; some can be observed towards the base of the left (fœtal) horn and in the region of the corpus uteri, more particularly towards the cervix where the chorionic foids become smaller and less numerous than elsewhere and ultimately vanish, leaving the conical process of the chorion that occupies the cervix perfectly smooth. In this complete absence of folds at the posterior extremity of the chorionic sac in specimen A, the placenta eonforms to the type "placenta en cloche," as originally described in Propithecus by Milne Edwards (1).

The chorionic sac of specimen B was figured by Hubrecht (10, pl. GG, fig. 151). It had been opened dorsally from a point opposite the lumbar region of the fœetus to the head. In all essential features it resembles that of specimen A. The laminar folds are fairly evenly distributed upon the suiface of the sac opposite the right side of the fotus (Pl. III. fig. 4); they are closely crowded together, and are arranged for the most part transversely to its long axis. Towards the hinder end they become (as in specimen A) less continuous and less closely packed than further forward, and show four areas apparently bare, but in reality covered with fine ridges and grooves, giving an appearance of fine striation (Pls. III., IV. figs. 4 \& 10). Opposite the left side of the fœtus (Pls. III., IV. figs. $5 \& 7$ ) is the process or appendage, as 
we term it, of the chorionic sac that occupied the right horn of the uterus. Upon its surface the chorionic folds reach their maximum (as in specimen A), and display strongly marked secondary folds and convolutions (Pl. IV. figs. 7, 8, \& 9). Elsewhere upon this face of the chorion, and more particularly opposite the head of the fœetus, the folds are relatively weak, and form low ridges separated by wide smooth areas; similar bare places also occur opposite the postero-dorsal aspect of the fœitus.

In comparison with the condition of the chorion in other Madagascar Lemurs, the strong lamination of the appendage that occupies the right (non-fœetal) born of the uterus is worthy of notice, This prolongation of the chorionic sac may be absent even at near full term (Anthony, 12, p. 247, Propithecus), and apparently, as a rule, enters the non-fœtal horn only as pregnancy advances (Turner, 5, pp. 578, 587; Anthony, 12, p. 247), and is normally less strongly laminated than other parts of the sac.

\section{Allantois.}

The allantois, as in other Lemurs, is a voluminous and characteristically lobulated organ whose cavity, though extensive in the circumferential plane, is flattened radially between the chorion with which its outer wall is fused and the amnion which is fused with its inner wall. Between the entodermal lining of the allantoic sac and the trophoblast of the chorion is situated a layer of delicate fibrillar connective tissue, formed from the allanto-chorionic mesenchyme and prolonged to form the axes of the villous folds. In it run the numerous branches and factors of the allantoic arteries and vein on their way to and from the subtrophoblastic capillary plexus, presently to be described.

The allantois consists of a main lobe, into which the allantoic canal opens and which accordingly represents the primitive allantoic vesicle, and of a number of accessory lobes of irregular shape, which have grown out from the primary sac and approach one another across the rump and back of the foetus. In specimen A the relations of the main sac and its various lobes to the underlying fotus were ascertained by carefully dissecting away the chorion. Two views of the preparation * so made are shown in $\mathrm{Pl}$. II. figs. 2 and 3 (cf. also textfigs. $2 \& 3$ ), representing the left and right sides respectively of the fœtus.

The main lobe (partially opened in text-figs. $2 \& 3$ and Pl. II. figs. $2 \& 3$ ) lies upon the left side of the posterior trunk region of the fœtus, and extends across the ventral surface some little way beyond the mid-line on to the right side, covering the feet and tail. It communicates with the allantoic canal, which runs down in the umbilical cord, by a small slit-like aperture, situated opposite the gap between the left knee and elbow. 
From the dorsal margin of the main cavity three accessory lobes stretch across the left aspect of the fœtus (text-fig. 2 and Pl. II. fig. 2): (a) a posterior lobe that runs caudally nearly to the midline of the amniotic sac; $(b)$ a dorsal lobe that covers the flank and sacral regions of the fœtus and extends for a short distance beyond the dorsal mid-line; $(c)$ a cephalic lobe, of sausage-shape, that passes directly towards the hear of the fotus across the shoulder as far as the root of the left ear. At the base of this lobe is a small ventrally directed subsidiary pocket.

Text-figures $2 \& 3$.
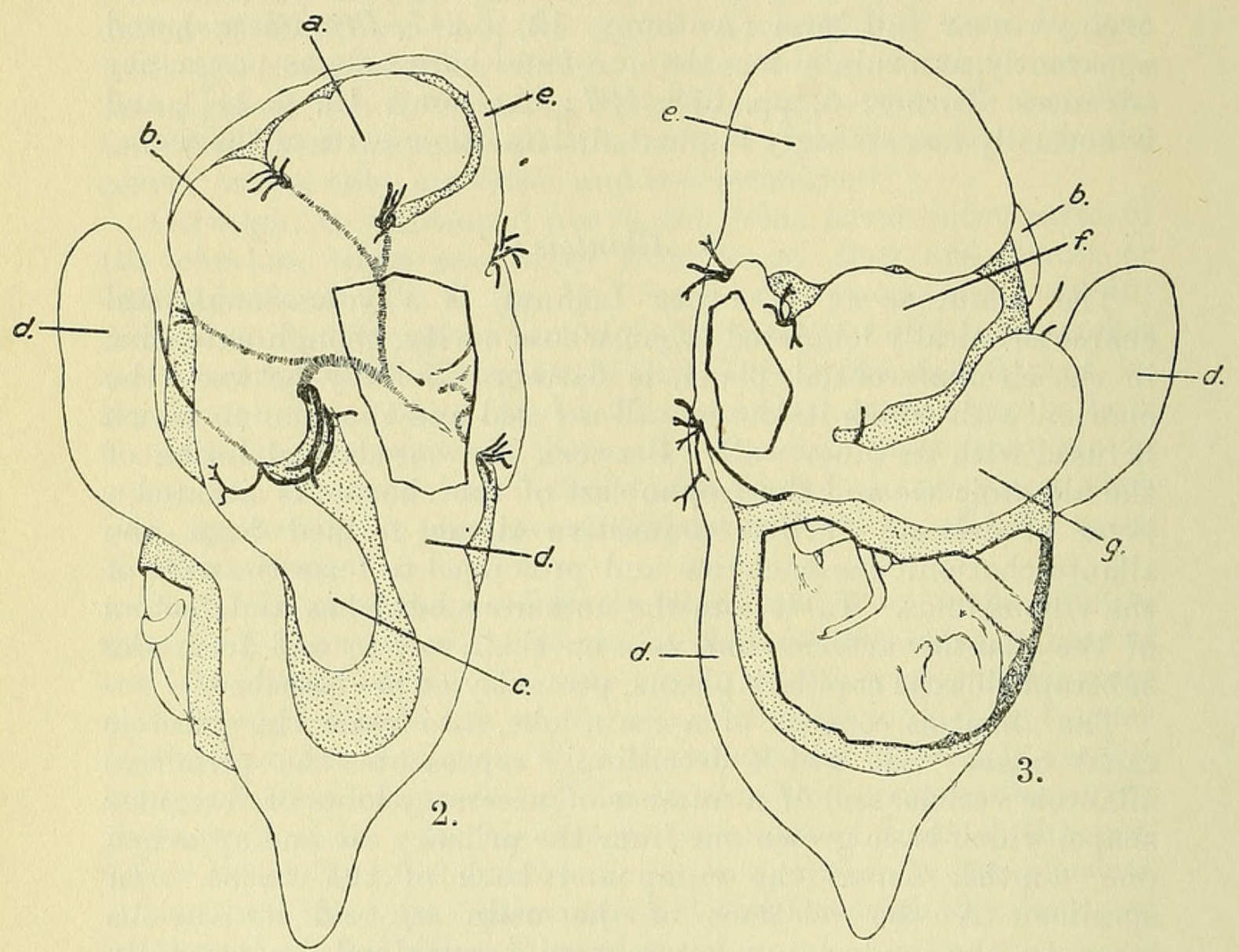

Spec. A, from left and right sides respectively, of fœtus, after removal of chorion, to show the main and accessory lobes of allantois.

The cephalic margin of the main cavity gives rise to but one lobule $(d)$, an extensive finger-shaped sac folded back upon itself in the form, roughly, of a $Y$. The sac runs at first cephalad across the left eye of the fœtus, and then is reflected round the cephalic pole of the amniotic sac, giving off at its furthest point a blunt conical process (the tail of the $\boldsymbol{Y}$ ) that extends into the similarly shaped prolongation of the chorionic sac that occupies the cervix uteri. After thus curving round the cephalic pole of the amnion, the lobule $d$ passes caudad along the dorsal surface 
of the fœtus, and leaving the amnion extends into and fills the chorionic appendage that lies within the unoccupied right horn of the uterus. Turner (5, p. 577) states that in L. rufipes the allantois does not extend into "the short diverticulum of the chorion which occupies the non-gravid horn." In specimen B we find a similar condition. The terminal process of the lobule extended to the mouth of the chorionic appendage and fitted closely within its lip, but did not project further into its cavity.

From the ventro-caudal margin of the main cavity arises a lobe $(e)$ that curves round the ventral surface of the caudal end of the fœtus, covering the root of the tail and the right hind limb and reaching to within a short distance of the free margins of lobes $a$ and $b$.

Upon the right side of the fœtus (Pl. II. fig. 3 and text-fig. 3) the main cavity gives off from its dorsal border two lobes ( $f$ and $g$ ) that pass towards the dorsal mid-line across the lumbar and thoracic regions of the fœtus. The caudal of these extends rather more than half-way towards the mid-line of the back; the other $(g)$ is a larger, sausage-shaped sac, that dilates gradually from a comparatively narrow origin to a bluntly rounded extremity and terminates upon the back of the foetus in contact with lobe $d$, at the point at which the latter leaves the amnion to enter the appendage of the chorion.

Apart from the narrowness of the commencement of this lobe, there is no indication in the allantois of the pedunculated subsidiary lobes mentioned by Milne Edwards (3) as occurring in Propithecus.

The umbilical cord was exposed in specimen B (Pl. III. fig. 6). It measured $4.3 \mathrm{~cm}$. in length, and at its emergence from the body of the fœtus was subcylindrical. At about the middle of its length it became more fiattened, appearing as a ribbon-like band, some $6 \mathrm{~mm}$. in width, bordered on each side by a thinner selvage. It joined the inner wall of the main allantoic lobe over the right latero-dorsal surface of the fœtus, running, attached to the wall, for a distance of about $1.5 \mathrm{~cm}$. before finally disappearing. In specimen $A$, the cord passed to the left side of the fœetus to reach the main lobe.

The cord (Pl. V. figs. 13, umb.c., \& 14) consists of a connectivetissue matrix, in which are situated the allantoic canal and the umbilical vessels. It is invested by the amnion, the epithelial layer of which is quite thin, resembling in places a cuticular membrane, and below this is a thin layer of connective tissue, rich in cells and not everywhere clearly marked off from the connective tissue of the cord. The allantoic canal (all.con.), situated between the vessels, possesses a wide lumen, lined by a two-layered epithelium of the transitional type. There are three umbilical vessels, two arteries, and one vein. The two arteries (Pl. V. fig 14, umb.art.) contain blood, and their walls are histologically similar, each possessing a compact zone of smooth muscle just outside the 
lining endothelium. The vein (fig. 14, umb.v.) is empty, and its wall lacks the compact zone of musele and appears contracted and its lining folded.

Epithelial pearls occur below the amniotic investment of the cord in the region of its junction with the allantoic sac, and are probably derived from the amniotic epithelium, since they are also occasionally found below the amnion covering the inner wall of the allantois adjacent to the cord-junction.

From the junctional region, branches of the umbilical vessels pass off to run in the inner wall of the main allantoic sac. Some of these after a short course reach the allanto-chorionic connective tissue directly in specimen $B$, by way of three septal pillars (figs. $13 \& 14$, sept.) which extend obliquely across the lumen of the main sac between its inner and outer walls, as Strahl appears to have observed in Galago (14, p. 182). In specimen A, these septa appear to be absent. Other branches after a straight or slightly branched course reach the allantochorion by passing round the margin of the main sac. They are seen emerging in Pl. II. figs. $2 \& 3$ and text-figs. $2 \& 3$ in the angles of the clefts between the main and accessory lobes. Yet other branches run straight on from the inner wall of the main sac to supply those regions of the chorion that are not underlain by prolongations of the allantois. In the chorionic connective tissue, the vessels subdivide and run in all directions to supply the subtrophoblastic capillary plexus of the laminar villi.

Both Milne Edwards (3) and Anthony (12) state that the allantoic walls in the Lemurs examined by them are devoid of blood-vessels. That, of course, is an erroneous statement as applied to the allantois as a whole, but it is partially true of the accessory lobes, since the inner walls of these (remarkably delicate and thin, as Milne Elwards remarks) are quite devoid of vessels. Thus it is an unexpected and somewhat remarkable fact that these accessory allantoic lobes in the Lemurs are not really concerned with the vascularization of the chorion, and the question arises as to their possible significance. One of the functions of the allantois is to serve as a receptacle for the urinary fluid excreted by the mesonephroi, and it is possible that the formation of these lobes is to be correlated with the presence in the fœtus of actively functional mesonephroi. In this connection it is interesting to note that Hubrecht (11) records that in the $6-\mathrm{mm}$. embryo of Nycticebus, the glomeruli of the mesonephros are remarkably large.

Whatever may have been the inciting cause of the growth of the allantois, there can be little doubt that its lobulated form is, as Milne Edwards (3, p. 283) suggested, a direct result of the position early assumed by the umbilical vessels on the walls of the main lobe, the first formed part of the organ. If that be so, then the actual form assumed by the allantois is a secondary matter and likely to be inconstant in its details, even in the 
individuals of the same age. From Milne Edwards's observations we know that in younger specimens it is simpler than in older.

It should be noted that the main sac and its lobes do not completely clothe the inner surface of the chorion (text-figs. $2 \& 3$ ), there being left between the lobes considerable areas where the amnion is fused directly with the inner surface of that membrane.

The entodermal lining of the allantois is formed by a well-marked cubical epithelium, quite different from that lining the allantoic canal. Its inner surface is not everywhere smooth, but is produced into low folds, more numerous in the main sac than in the accessory lobes. Its mesodermal wall is relatively thin, and consists of fibrillar connective tissue, dense just outside the entodermal lining, but delicate and loose elsewhere both in the inner and outer walls. In parts it is reticular in character. It is rich in cells both fixed and migratory.

\section{Yolk-sac.}

We have not found any definite traces of the yolk-stalk and yolk-sac in our specimens, unless an irregular epithelial strand in process of cornification, which is situated below the amnion of the umbilical cord in the region of junction and bounded on its inner side by a mass of gelatinous connective tissue, represents the degenerate remains of the stalk. Milne Edwards (3) figures the yolk-sac in relatively late fœtuses of Propithecus diadema and Indris brevicaudatus ( $v$. especially his pl. 120, where in a late but not yet haired fotus of the latter species it is shown as a quite small, flattened, and stalked vesicle, situated towards the distal extremity of the allantoic stalk-i.e., approximately in the position of our cornifying strand). Strahl (14) simply mentions that in a $36-\mathrm{mm}$. foetus of Galago the yolk-sac is "gut nachweisbar." Jenkinson (16) states that in Lepilemur "no trace of the yolk-sac was found."

\section{Amnion.}

The amnion forms an oval sac fitting loosely around the fœtus. It invests the umbilical cord throughout its length, and at the distal extremity of that spreads out to become loosely fused with the inner wall of the allantoic sac and its lobes. In the intervals between the latter it is fused directly with the connective tissue of the chorion. The most extensive areas of the amnion that are in this way in direct apposition and fusion with the chorion lie towards the head-end of the fœtus (text-figs. $2 \& 3$ and Pl. II. figs. $2 \& 3$ ). There is an extensive area covering the whole of the right side of the head and shoulders (text-fig. 3), and narrower patches over the left side of the head and shoulders (text-fig. 2) and along the back between the apices of the allantoic lobes. As in the higher Primates, the expansion of the amniotic sac and its adherence to the inner wall of the allantois have brought about the complete obliteration of the extra-embryonal cœlom.

Proc. Zool. Soc.-1922, No. LXXVII. 


\section{Minute Structure of the Allantoic Chorion and its Villi.}

The general appearance of the chorion and its villi in section is illustrated in Pls. V., VI. figs. 13, 14, and 15.

The allanto-chorion consists essentially of the outer wall of the allantois fused with the chorion proper. It thus comprises the following layers:-(1) the allantoic entoderm; (2) the composite allanto-chorionic connective tissue which is continued out to form the cores of the complexly folded laminar villi, and in which are situated the branches of the umbilical vessels; (3) the superficial covering of trophoblast (tropho-ectoderm, chorionic ectoderm).

The trophoblast : fig. 16, ir.) throughout its extent is singularly uniform in character, varying only in thickness, and that with no apparent regularity, though frequently it is thinned in places over the apices of the villous branches. It attains a maximum thickness of $\cdot 024 \mathrm{~mm}$. and a minimum of $\cdot 005 \mathrm{~mm}$. or even slightly less. Where it is thickest, it consists of a well-defined single layer of cubical cells, with their outer surfaces projecting convexly. The nuclei are large and deeply staining. The cytoplasm of the outer zone of the cell-body is homogeneous or very finely granular and strongly eosinophil; that of the deeper zone below the nucleus is reticular in character, and stains lightly. There is no basement membrane, and the basal ends of the cells rest, just like those of the uterine epithelium, directly on the endothelial walls of the underlying capillaries (iig. 16, cap.). These are relatively large and very abundant, forming a richly developed subepithelial plexus, first figured by Milne Edwards from injected specimens of Propithecus diadema and Indris brevicaudatus (3, pl. 121, figs. 1, 2, \& 4). In Galago also, according to Strahl (14), the capillary network of the villi lies in direct contact with the epithelial covering.

The mesodermal core of the villi (Pl. VI. fig. 16) is formed by a variety of fibrillar connective tissue, differentiated into two zones: (a) a looser less deeply staining central zone (c.t.), containing numerous leucocytes and lymphocytes and in which are situated the smaller branches of the umbilical vessels; and $(b)$ a highly characteristic peripheral zone in the form of a perfectly continuous and more deeply staining layer of uniform thickness which lies immediately below, and evidently forms a support for the subtrophoblastic capillary plexus. This peripheral zone (Pl. VI. fig. 16, c.t'.) consists of a coarse fibrous reticulum, the stronger fibres of which run out at right angles to the surface, so that under a low power the zone presents a striate appearance, suggestive at first sight of a columnar epithelium, more especially as the nuclei of its cells of origin are mainly arranged in an irregular row, defining the deep surface of the zone. Round the nuclei there is sometimes visible a small amount of cytoplasm, which appears to be directly continuous with the fibrous network. This zone would seem to be ristinctive of the villi of Chiromys. It is not present either in Lepilemur or Nycticebus. In both these forms the 
trophoblast is very similar to that of Chiromys, but in neither of them is the subtrophoblast capillary plexus anything like so well developed, the capillaries being smaller and much less numerous than in Chiromys.

We have, unfortunately, no preparations of Chiromys which show the relation of the villi to the folds of the uterine mucosa, and are thus unable to state definitely whether the interdigitation of the two was of the same intimate nature as occurs in Lepilemur (Jenkinson, 16) and Propithecus coronatus (Strahl, 15), or was of a looser character, approximating to the conditions we find in Nycticebus. In the latter, Assheton states that "the fœetal villi appear to hang in grape-like bunches into the mouths of much wider depressions" (18, p. 269); and the sections certainly suggest that considerable areas of the lateral surfaces of the villi do not come into contact with the uterine folds, and that intimate apposition between the trophoblast and the uterine epithelium is largely limited to the flattened surfaces of the ends of the villi. In this connection it is worthy of note that glandsecretion is present in fair abundance round the proximal portions of the villi. In Galago, Strahl (14) states that over the tips (except in the region of the terminal pits) and lateral surfaces of the villi the trophoblast and uterine epithelium are firmly attached to each other, but in the intervillous intervals the connection is less intimate.

In Lepilemur, the villi are somewhat similar in character to those of Chiromys, but are readily distinguishable therefrom, being much less coarse and more finely branched. The mucosal folds are likewise very thin, as is the case also, according to Strahl (15), in the 60-65-mm. fœtal stage of Propithecus, whilst their relations to the villous folcs are exceedingly intimate. In our sections of Lepilemur, the uterine epithelium, practically everywhere in the villous regions, has become separated from the underlying connective tissue of the mucosal folds, and is seen as a relatively thin layer in close and intimate apposition with the thicker, more cubical trophoblast. In Propithecus, Strahl (15) also describes the two epithelia as being in close contact. In Chiromys, we incline to believe that the relations between uterine epithelium and trophoblast were not throughout quite so intimate as in the two Lemurs just referred to.

\section{Chorionic Vesicles.}

When the deep surface of the allanto-chorion is examined after reflection of the inner wall of the allantois, numbers of small, flattened, ovalish bodies of a reddish-brown colour may be seen embedded in its substance (Pl. VI. fig. 11). These are the chorionic recesses first described and figured by Hubrecht (8) in Nycticebus, and later described by Strahl (14) for Galago, where he designated them "chorionic vesicles."

These bodies were encountered in both our specimens, but 
they were larger and more easily seen in specimen B than in specimen A. They varied considerably in size, the largest measuring $5.5 \times 4.5 \mathrm{~mm}$. in diameter, the smallest $1.5 \mathrm{~mm}$. They numbered about sixty, and were chiefly distributed upon the parts of the chorion that overlay the head region of the fotus, being more numerous on the right side than on the left.

In specimen $\mathrm{A}$, although a few of these bodies were as large as in specimen B, the majority were no larger than a pin's head. Most of them were located upon that part of the chorion which occupied the left uterine horu, being particularly numerous upon those areas where the chorionic laminæ were most richly developed. Few, if any, could be located with certainty on the chorion within the right horn and the body of the uterus.

In the sections (P1. V. figs. $13 \& 14$, ch.ves.), the vesicles are seen to be siturted either in the allanto-chorionic connective tissue, close to the allantoic lumen, or actually in that of the laminar villi. The vesicle is of simple structure, and unlike those of Nycticebus and Gralago, is devoid of villous folds or ingrowths projecting into its cavity. Its opening is small and slit-like (Pl. V. fig. $13, o p$.). Lining the cavity is a single-layered epithelium, representing an involuted portion of the trophoblast, but differing from that in its characters. It consists of low cubical to flattened cells, .013 to $.008 \mathrm{~mm}$. in thickness. The eytoplasm of the cubical cells is reticular in character, and encloses one or more large vacuoles. The nuclei are mostly basal in position, and frequently appear shrunken and irregular. The lining rests on a very thin, comprct layer of fibrillar connective tissue. It is noteworthy that the vesicle-wall appear's to be entirely devoid of capillaries. The cavity is occupied more or less completely by a coarsely granular coagulum, no doubt representing the secretion of the uterine glands, and in it there occur, here and there, degenerating cells, probably derived from the lining epithelium.

The chorionic vesicles of Nycticebus and Galago described by Hubrecht and Strahl are more highly differentiated than those of Chiromys, and would seem to be specially adapted for the collection and absorption of the secretion of the uterine glands (Strahl, 14). In our sections of Nycticebus, we find the vesicle invested externally in a fairly dense fibrous connective-tissue coat, in which there are present numbers of larger and smaller blood-vessels. The lining of the sac is formed by a flattened to cubical epithelium, in contact with the under surface of which there are here and there fair-sized capillaries. The cavity of the vesicle is largely occupied by vascular villi as described by Hubrecht, clothed by an epithelium similar to that lining the cavity, and between the villi is a granular material similar to that found in the uterine glands.

In Galago, Strahl (14) described the occurrence of similar vesicles, but found that their openings, unlike those of Nycticebus, overlie depressed areas of the mucosa on which are the openings of uterine glands. 
In Chiromys, the vesicles are evidently not of the same functional importance as in Nycticebus and Galago, and it may be suggested that they serve not so much as absorptive organs, but rather as reservoirs for the surplus of the uterine-gland secretion which is probably in major part absorbed directly by the trophoblast of the laminar villi.

The general occurrence of chorionic vesicles in the Lemuriformes has not so far been established. The only reference to their presence that we know of is an inconclusive statement by Strahl (15) that in Lemur mongoz, he observed at one place an indication of a chorionic vesicle devoid of internal villi, orerlying a groove in the mucosa which might be a uterine gland area. But what apparently does characterise the chorion of certain of the Madagascar Lemurs, e. g. Propithecus, is the occurrence of circumscribed chorionic bare patches, opposite which there occur on the mucosa depressed bare areas on which the uterine glands open. Such complementary bare areas (and more especially the uterine) have been described by Milne Edwards and Turner (with excellent figures of the uterine areas, 3, p. 280, and 5 , figs. $8 \& 9$ ), and more recently by Strahl (15, figs. 14, 15 , $16, \& 18 a \& b)$, but none of these observers has given any account of the structure of the chorionic areas, though Turner $(5$, p. 582) expressly states that " the smooth, non-villous surfaces of the chorion opposite the smooth areas on the mucosa are engaged in the absorption of the secretion of the glands."

In the course of examining our preparations of the late Dr. Jenkinson's material of Lepilemur, we observed what we took to be these particular areas; and on referring again to Dr. Jenkinson's paper, we realised that his description (16, p. 180), of the simpler conditions in what he terms "the non-placental [really non-villous] regions," illustrated in his figs. $3-7$ and 15 , actually refers to the areas which we had identified as the bare areas of previous investigators. As Jenkinson describes, these non-villous areas are characterised by the transformation of the trophoblast covering them, into a thick layer composed of elongated narrow columnar celis, measuring up to $.063 \mathrm{~mm}$. in height and just about six times as thick as the normal trophoblast covering the villi (c\%. Jenkinson's figs. 3, 4, \& 5). The cytoplasm of the cells is lightly staining and coarsely reticular in character, and in some of the cells there is a large, clear vacuole situated in the basal part of the cell, below the nucleus. The nuclei are oval and deeply staining, and are situated near the middle of the cell-bodies, though sometimes they approach their free surface. Occasional binucleate cells were observed. Specially characteristic of this epithelium is the production of the outer ends of the cells into bluntly tapering or knob-shaped processes, in which, occasionally, a more or less shrivelled nucleus may be seen. They project into a granular material, "apparently a secretion of the uterine epithelium," according to Jenkinson, and are no doubt absorptive in function. In the basal part of the 
layer, there occur at intervals curious spherical cells, and immediately below it, capillaries are present in fair abundance.

The uterine areas, related to the just-described characteristic areas, are more or less folded, and may or may not be depressed. They are characterised by the marked thickening and ridging of the nterine epithelium, and by the presence of the openings of the uterine glands. The uterine epithelium appears as a deeply staining layer, thrown into low ridge-like folds (Jenkinson, fig. 15) and about five times as thick as the ordinary epithelium covering the mucosal folds. It is composed for the most part of narrow columnar or club-shaped cells, with deeply staining cytoplasm and chromatin-rich nuclei. Jenkinson records the presence of goblet cells amongst the ordinary epithelial cells, but we have failed to detect them, and considers the epithelium is secretory. However that may be, and it is probable, coarsely granular material similar to that found in the uterine glands occurs in the interspaces between the thickened trophoblast and the ridged uterine epithelium ; and there can be no doubt, we think, that these non-villous chorionic areas have the same functional significance as the chorionic vesicles of the Lorisiformes. Indeed, in view of the close adherence of the uterine epithelium to the trophoblast of the chorionic villi, characteristic alike of Propithecus (Strahl) and Lepilemur (Jenkinson), special absorptive areas in relation to the openings of the uterine glands would seem to be necessary if the secretion of the latter is to be adequately utilised.

It may be noted that these areas attain a relatively considerable size, as may be judged from Strahl's figures of Propithecus (15, taf. 37). The largest area we have examined in Lepitemur measures over $3 \mathrm{~mm}$. in diameter.

\section{Conclusion。}

In the contribution by one of us $(H$.$) to the discussion on the$ zoological position and affinities of I'arsius (1\%), the view is expressed ( $p .477$ ) that the placentation of the Lemuroids is essentially primitive, "presenting us with a simple little specialised type of placenta from which the more advanced and presumably more efficient arrangements in the other Primates may quite easily have originated as the result of adaptive specialisation in the course of evolution." More detailed acquaintance with the Lemuroid placenta has only served to strengthen us in that conclusion, and has, moreover, entirely failed to reveal the slightest evidence in support of the view expressed by Hubrecht (10, p. 145) and also by Assheton $(18$, p. 268$)$ that the Lemuroid placenta is a secondarily simplified and derivative type.

These two authorities base their belief very largely on theoretical considerations concerning placental evolution, and consider that the diffuse placenta of the Lemurs is different from that of the Ungulata, Manidæ, Cetacea, etc. 
In his speculations on the phylogeny of the placenta, Hubrecht (10) starts out by denying a Reptilian origin for the Mammalia, and postulates a primary phagocytic and absorptive activity on the part of the trophoblast. From the very start of uterine gestation, the trophoblast proliferating rapidly, invaded and destroyed the maternal decidual tissue, and as the result, there was formed a localised placenta of the "deciduate" type in which the maternal blood circulated either in endothelially lined capillaries enclosed by trophoblast (Carnivora) or actually in lacunar spaces in the trophoblast itself (Insectivora, Rodents, etc.). That being the primary and original type of placentation, it follows that all the "diffuse" varieties of placenta in which such phagocytic activity on the part of the trophoblast "was insignificant or absent (Lemurs, certain Edentates, and many Ungulates)" have been derived by simplification from the more elaborate "deciduate" type. Hubrecht admitted, however, that "we cannot for the present indicate the intermediate steps by which the simplification of a placenta of the Insectivorous or Primate type down to that of the present Lemurs was brought about ..." (10, p. 115); but he saw "no reason why this simplification should not have arisen more than once" (p. 145)--i.e., the diffuse placentation of Lemurs " was not necessarily obtained along the same hereditary line of development" as that of Ungulates. Indeed, he thinks there is sufficient evidence to justify the drawing of a sharp line of distinction between the placentation in these two groups. The late Richard Assheton, in his critique of Hubrecht's monamental paper (10), says (18, p. 268): “I entirely agree with Hubrecht's opinion that the diffuse placentation of the Lemurs is different from that of the true plicate * forms of Ungulates, Cetacea, some Edentates, etc." Further he writes (p. 265): "Whether the Carnivora or the extreme cumulative or extreme plicate [placenta] is the most primitive, it is very dificult to say"; nevertheless he goes on to suggest that the Lemurine placenta, which he terms "pseudo-plicate," may possibly have been derived by reduction from a cumulate type such as is found in the Carnivora, "by way of such conditions as Hylobates, Semnopithecus, Cercocebus, by the gradual supersession of the glandular activity of the maternal uterus over the phagocytic activity of the fotal trophoblast, and the filling of the blood spaces, into which the foetal villi originally hung, with uterine secretions instead of extravasated maternal blood" (p. 269). But why the Lemurs after having evolved a cumulate (deciduate) placenta should have been under the necessity of substituting for it the plicate (non-deciduate) type is not explained.

* Assheton suggested a grouping of placental forms based on the behaviour o the trophoblast into $(a)$ Cumulate, characterised by radial, more or less loca thickening of the trophoblast which is actively phagocytic (= "Deciduate") (b) Plicate, characterised by tangential extension and folding of the trophoblas with little or no phagocytic activity (="Nondeciduate"). 
We must confess we are quite unable to accept the views of these two authorities, either in respect of the secondary nature of the diffuse placenta of the Lemurs or in regard to its dissimilarity to the diffuse placenta of other Mammals. It appears to us they have attempted to read the story of placental evolution the wrong way round.

In our opinion, any attempt to trace the evolution of mammalian placental arrangements must be based on a consideration of the probable conditions which obtained at the time viviparity replaced oviparity. Knowing the arrangement of the fœtal membranes in the existing Monotremes, we can picture the conditions with reasonable certainty. We snould postulate, then, that the common ancestral stock, from which the Didelphia and Monodelphia diverged, possessed an arrangement of the fotal membranes similar to that of the existing Monotremes and of Phascolarctos amongst the Marsupials--i.e., the outer wall of the embryonal formation consisted as to one-half or thereabouts of unsplit blastocyst wall or omphalopleure, in part vascularised by the vitelline vessels of the vascular area of the yolk-sac, and as to the remainder, of allanto-chorion, vascularised by the umbilical vessels of the vesicular allantois. The uterine mucosa possessed a persistent covering epitheliuin, functional uterine glands, and a rich vascular supply.

These being the structural elements involved, the primitive placenta was constituted simply by the close apposition of the omphalopleure and the allanto-chorion with the vascular lining: of the nterus. Here we have the simplest possible type of placenta, partly allantoic, partly vitelline and diffuse in the sense that the whole of the outer surface of the embryonal formation is involved in the carrying on of the exchanges between the maternal and fœtal blood-streams. The trophoblast covering the entire outer surface is as yet a simple layer, absorptive but not actively phagocytic.

Out of the primitive placenta here outlined, we see no difficulty in deriving on the one hand, the relatively simple placental arrangements characteristic of the Marsupialia and on the other, the varied types of placenta characteristic of the Monodelphia, the non-deciduate diffuse type representing only a relatively slight elaboration of the primitive form, and the varieties of the "deciduate" type resulting from the assumption by the trophoblast of active phagocytic properties, the precise characters assumed by the placenta being in all cases determined by a variety of conditions, intrinsic and environmental or uterine. We therefore remain firm in our belief that the placentation of the Lemurs is genuinely simple and little specialised.

Finally, as concerns the reputed distinction between the Lemuroid diffuse placenta and that of other Mammals, we readily grant there are differences in detail, but we quite fail to see that there is any fundamental difference, or ever enough difference to justify the calling of the former "pseudo-plicate" 
and the latter "plicate." Both are plicate in Assheton s sense, and are characterised on the fœtal side by the presence of a relatively passive trophoblast, markedly folded and of great extent, by the vascularisation of the chorion through a large vesicular allantois and by the reduction of the yolk-sac and its vessels; and on the maternal side, by the persistence of the uterine epithelium (at least in the majority) and of the uterine glands in an active functional condition. In our view, the resemblances far outweigh the differences in detail.

We are accordingly in entire agreement with Jenkinson (16) in believing (1) that the resemblance between the non-deciduate placentation of the Lemuroids and that of other Mammals, e.g. the Ungulata, are due to their derivation "from a common ancestral 'indeciduate' type"; and (2) that the deciduate hæmochorial type of placenta characteristic of the other Primates has been evolved from the non-deciduate Lemuroid type, quite independently of that of the Rodents. Insectivora, etc.-another illustration of the principle enunciated by H. F. Osborn that "the same results appear independently in descendants of the same ancestors."

We are greatly indebted to Mr. F. Pittock for invaluable help in the preparation of Pls. III.-VI. and to Mr. S. Steward for the photographs of Specimen A, Pls. I. \& II., and to Mr. Terzi for retouching the same.

\section{APPENDIX.}

On the External Characters of a Fœtal Chiromys.

$$
\text { By R. I. Pocock, F.R.S. }
$$

At the request of the authors, I undertook to examine and describe the external features of the foetal Chiromys (Specimen B, Pl. III. fig. 6), the placenta of which is described in the preceding pages by Prof. Hill and Mr. Burne.

The approximate dimensions in millimetres of the specimen, a male apparently at full time, are as follows:-Dorsal contour length (snout to root of tail) 165; head and body from crown to root of tail 106; head from nose to occiput 37 ; ear from intertragal notch 21 ; tail 103 ; upper arm 25; fore-arm 21; paim of hand 12 ; thigh 31 ; lower leg 31 ; sole of foot 18 . The general proportions do not differ greatly from those of the adult, the tail and arm being relatively as long, but the head is relatively larger, the leg shorter, and the digits of the hand shorter than in the adult.

The coat consists of comparatively short and sparse adpressed hairs, brown and grey in colour; on the hands and feet and tail 
the tint is blacker; the muzzle and cheeks are nearly naked. In the adult the coat is thick and woolly and black in colour, with long black and white bristles intermixed. The head is relatively larger, and has a more vaulted cranium than in the adult.

The rhinarium is well developed and like that of the adult. So also are the facial vibrissæ, the genal and superciliary tufts

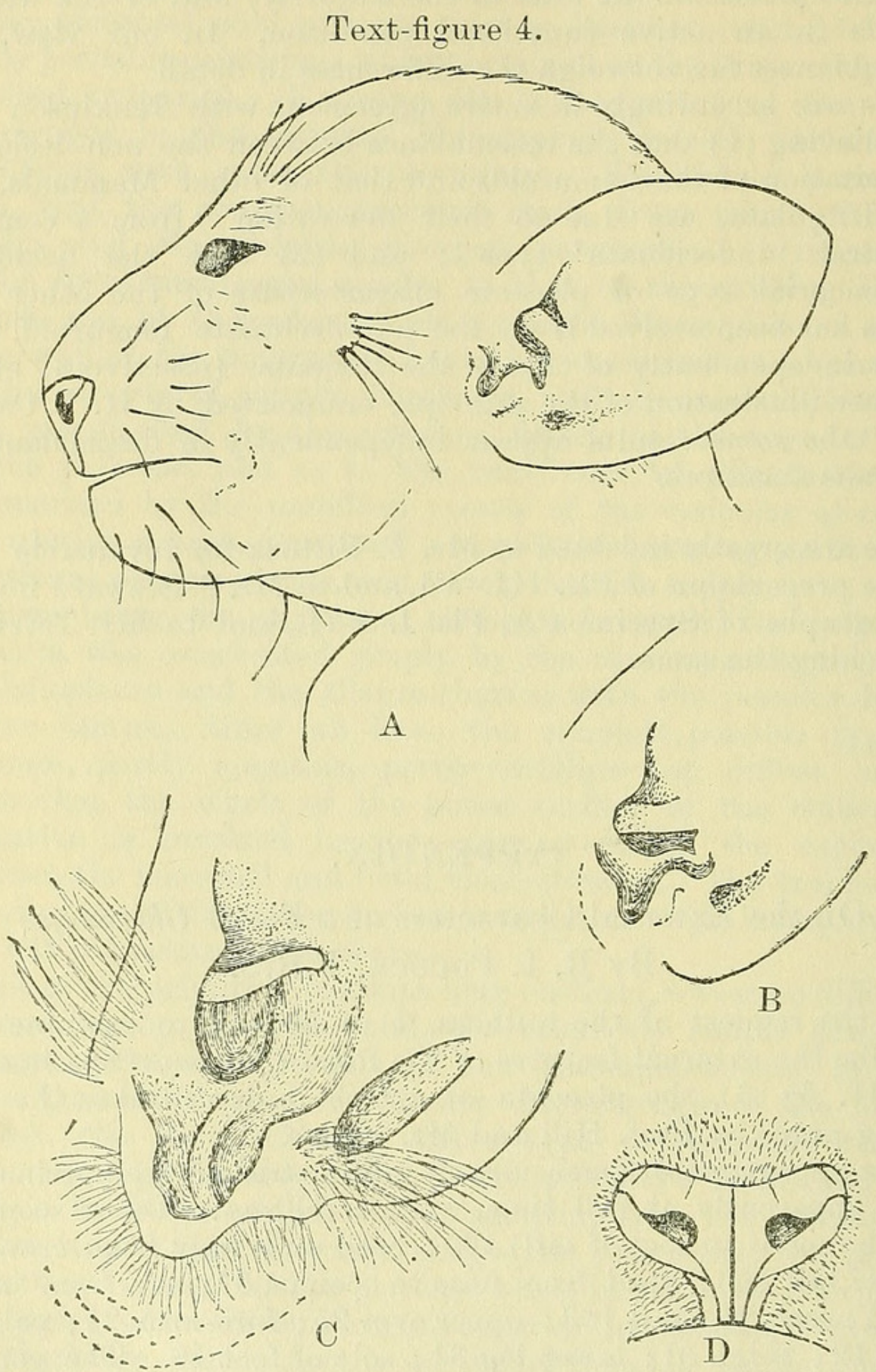

A. Head of foetal Chiromys. B. Base of ear of same. C. Base of ear of adult. D. Rhinarium of fotal Chiromys.

being specially well marked. There is a single interramal vibrissa. The eyes are much smaller than in the adult, oval and pointed at each end, like the eyes of a diurnal mammal. 
The ear is covered with short hair externally, and is flat and not hollowed, but the ridges and depressions characteristic of the adult are all indicated. In the adult the ear is naked internally and deeply hollowed; it is also relatively much larger than in the foetus, its length being equal to the distance between its intertragal notch and the end of the rhinarium, whereas in the young its length is only equal to the distance from the end of the rhinarium to a point just behind the eye.

The tongue differs in at least two particulars from that of the adult. The distal margin of the sublingua is irregularly pointed and serrulated, and the median inferior ridge ends in a soft straight point, not in a hard down-curved hook. In the points

Text-figure 5.

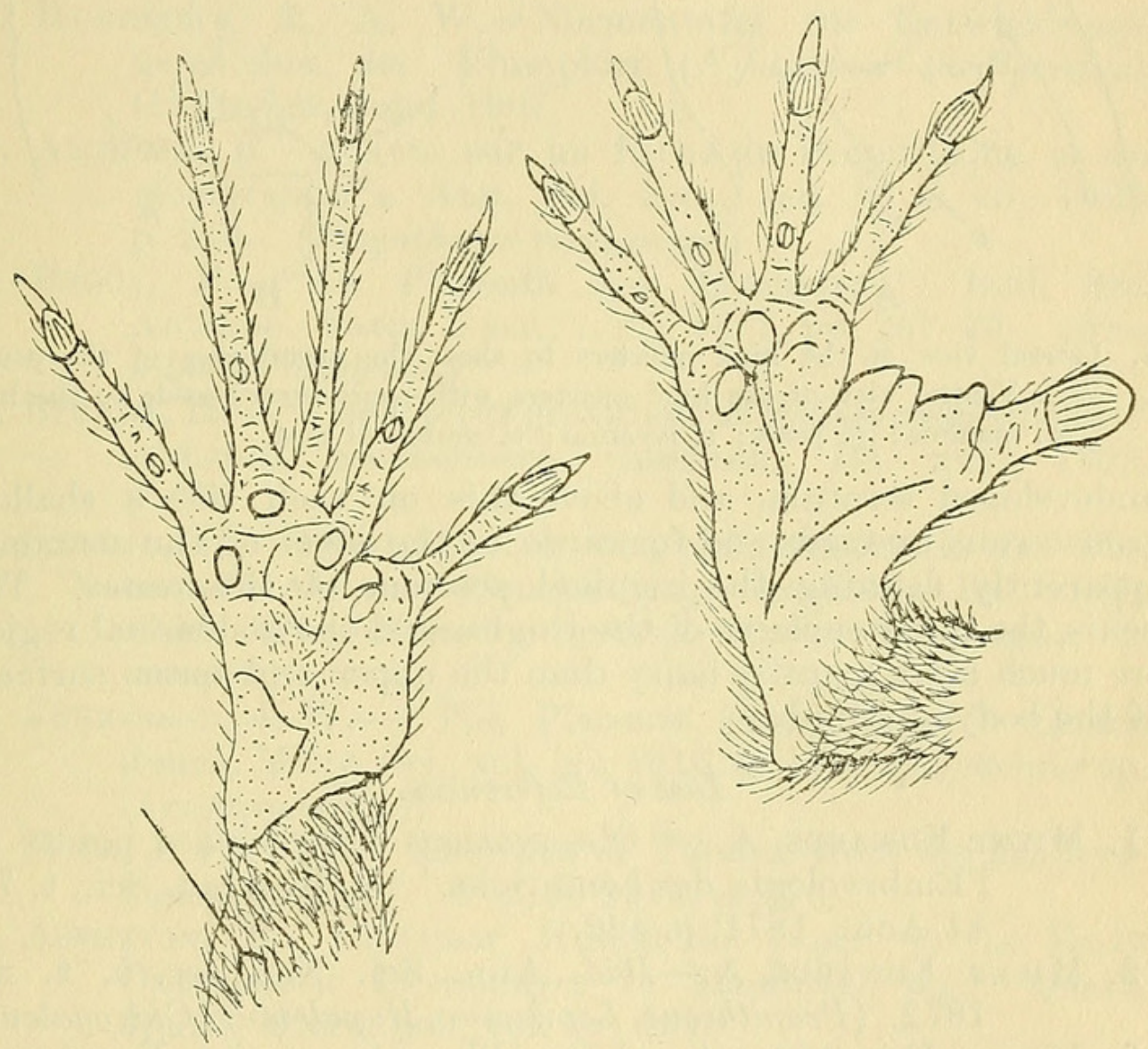

Hand and foot of fotal Chiromys.

in which the sublingua differs from that of the adult, it approaches the less specialised condition seen in the typical Lemurs.

The fore limbs closely resemble those of the adult, but the digits are relatively much shorter. The fourth digit, for example, is only a little longer than the palm, whereas in the adult it is nearly twice the length. The pollex also is relatively much nearer to the second digit than it is in the adult.

The hind limb closely resembles that of the adult in all important respects. It is, however, relatively shorter in all its parts. 
The external genitalia are remarkable for the length and thickness of the penis, the distal end of which is curved forwards, with its posterior, or inferior, stirface strongly convex. Proximally it arises in front between the two well-marked inguinal mammæ, and its integument here is mesially grooved. Immediately behind its posterior point of insertion there is a little bilobed thickening of the skin, representing the tip of the

Text-figure 6.

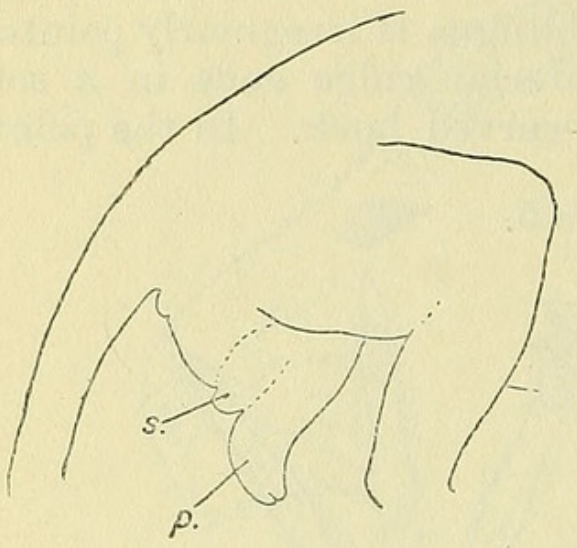

A

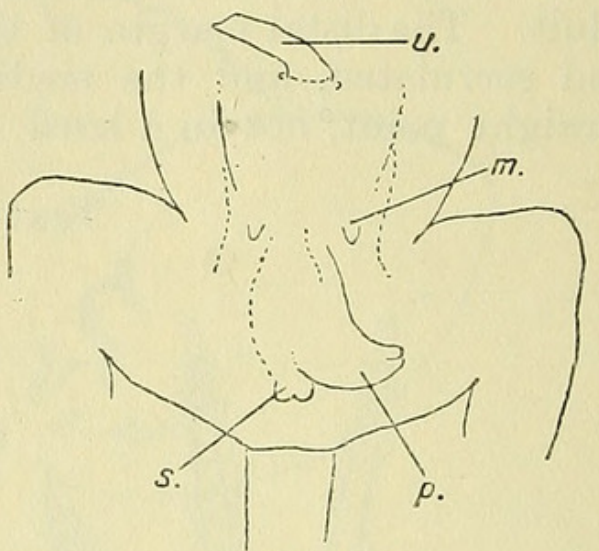

$\mathrm{B}$

A. Lateral view of the hind quarters to show the prominence of the penis. B. Ventral view of the hind quarters, with penis turned aside to the left. $m$. mamma; $p$. penis; $s$. scrotum; $u$. umbilical cord.

undeveloped scrotum, and above this on each side a shallow groove runs upwards and forwards to the level of the mammæ, apparently defining the inguinal position of the testes. The penis, the inner surfaces of the thighs, and the abdominal region are much more scantily hairy than the upper and outer surfaces of the body and limbs.

\section{List of References.}

1. Milne Edwards, A.- "Observations sur quelques points de l'Embryologie des Lémuriens." C. R. Acad. Sci., t. 73. 14 Août, 1871 , p. 422.

2. Milne Edwards, A.-Ibid. Ann. Sci. Nat. ser. 5, t. xv. 1872. (Propithecus, Lepilemur, Hapalemur, Chirogaleus.)

3. Milne Edwards, A.--"Du Placenta et des Enveloppes fœtales" (des Lémuriens). Chap. ix. : "Histoire Naturelle des Mammifères de Madagascar." T. i. \& Atlas, in Grandidier's 'Histoire de Madagascar,' vol. vi. Paris, 1875. (Propithecus diadema, P. edwardsii, P. verreauxii, Avahis laniger, Indris brevicaudatus.)

4. Milne Edwards, A.-"Sur la disposition des enveloppes fœtales de l'Aye-Aye." C. R. Acad. Sci. Paris, t. 99. 1884, p. 265. (Chivomys.)

5. Turner, W._- On the Placentation of the Lemurs." Phil. Trans., vol. 166. 1877, p. 569. (Propithecus diadema, Lemur rufipes, Indris brevicaudatus.) 
6. Turner, W.- "The Placentation of the Lemurs." Journ. Anat. \& Physiol., vol. xii. 1878, p. 147.

\%. Turner, W.- "An additional contribution to the Placentation of the Lemurs." Proc. R. Soc., vol. xliv. 1888, p. 277. (Lemur xanthomystax.)

8. Hubrecht, A. A. W.- "Spolia Nemoris." Quart. Journ. Micro. Sci., vol. xxxvi. 1894, p. 90. (Nycticebus tardigradus, Tarsius spectrum.)

9. Hubrecht, A. A. W.- "Ueber die Entwicklung der Placenta von Tarsius" etc. Proc.4th Internat. Congress, Zoology. Cambridge, 1899.

10. Hubrecht, A. A. W.- "Early Ontogenetic Phenomena in Mammals" etc. Quart. Journ. Micro. Sci., vol. liii. 1909, p. 168.

11. Hubrechr, A. A. W.-Normentafel zur Entwicklungsgeschichte des Plumplori (Nycticebus tardigradus). G. Fischer, Jena, 1907.

12. Anthony, R. - "Note sur un fœetus de Propithèque et ses membranes." Ann. Sci. Nat., ser. 9, t. vii. 1908, p. 243. (Propithecus verreauxii.)

13. Broca, P.- "Le Placenta des Lémuriens." Bull. Soc. Anthrop. Paris, 2 ser., t. xii. 1877, pp. 267-70. (Propithecus diadema.)

14. Strahl, H.- "Der Uterus gravidus von Galago agisymbanus." Abhandl. Senckenberg. Gesellsch., Bd. xxvi. 1902, p. 155 .

15. Strahl, H.-"Beiträge zur vergleich. Anatomie der Placenta." Abhandl. Senckenberg. Gesellsch., Bd. xxvii. 1904. (Propithecus coronatus, Lemur albimanus, L. mongoz.)

16. Jenkinson, J. W.-"The Placenta of a Lemur." Quart. Journ. Micro. Sci, vol. lxi. 1916, p. 171. (Lepilemur sp. (? ruficaudatus.))

17. Hill, J. P.-"The Affinities of Tarsius from the Embryological Aspect." P.Z.S. 1919, p. 476.

18. Assheton, R.-Professor Hubrecht's paper on the Early Ontogenetic Phenomena in Mammals, etc. Quart. Journ. Micro. Sci., vol. liv. 1910.

\section{EXPLANATION OF THE PLATES.}

\section{List of Reference Letters.}

all.c. allantoic cavity ; all.can. allantoic canal ; all.ch. allanto-chorion; all.ent. allantoic entoderm; all.w. inuer wall of allantois; amn. amnion; cap. allantoic capillaries; ch.a. chorionic appendage; ch.ves. chorionic vesicle; c.t. connective tissue of villus; c.t'. peripheral zone of same; $f d$. fold between uterine cornua; musc. muscularis; op. opening of chorionic vesicle; $p$. smooth prolongation of chorion into cervix ; sept. septal pillar between inner and outer walls of allantois; $t r$. trophoblast; umb.c. umbilical cord; umb.art. umbilical (allantoic) artery; umb.v. umbilical vein; ut.gl. uterine glands; vill. chorionic villus.

Fig. 1. Uterus, Chiromys, Spec. A., opened from the dorsal side, showing the chorionic sac in situ. The folded character of the mucosa, the chorionic appendage (ch.a.) projecting into the right cornu, and the non-villous prolongation $(p$.$) into the cervix are well seen. fld. fold between uterine$ cornua. About nat. size. 
Fig. 2. Fotal Chiromys, Spec. A. The chorion has been removed, exposing the main sac of the allantois and its accessory lobes on the left side of foetus. The head of the fœtus is towards the lower side of the plate. The main sac has been opened up, exposing the opening of the allantoic canal, into which a white rod has been passed. (Cf. text-fig. 2 and text, p. 1153.) Slightly reduced.

Fig. 3. Fœtal Chiromys, Spec. A. The same preparation as in fig. 2 , but from the right side of fœtus. An extensive area of the amnion on the right side of the head of the foetus has been removed. (Cf. text-fig. 3 and text, p. 1155.) Slightly reduced.

Fig. 4. Tiew of the chorionic sac from the right side of the fotus, Spec. B, showing the arrangement and character of the laminar villi. The head of the foetus is towards the left side of the plate. Slightly reduced.

Fig. 5. Similar view of the left side of the chorionic sac, Spec. B, to show especially the chorionic appendage which projected as in Spec. A into the right cornu. Slightly reduced.

Fig. 6. Fotus, Spec. B, from the right side, after removal from the fotal membranes. The severed umbilical cord is seen overlying the right fore-arm. Slightly reduced.

Fig. 7. Chorionic appendage, Spec. B, extended so as to show the folded laminar character of the villi of its upper surface. Slightly reduced.

Hig. 8. Portion of the same, more highly magnified. $\times$ about 6 .

Fig. 9. Portion of the exposed surface of the chorionic appendage, Spec. B, showing the convoluted appearance of the villi. $\times$ about 6 .

Fig. 10. Enlarged view of the portion of chorion, Spec. B, orerlying left side of hinder region of fœtus, showing the folded villi and the non-villous ridged areas. $\times$ about 6 .

Fig. 11. (Pl. VI). View of the inner surface of allanto-chorion after refiection of the inner wall of allantois (all.w.), showing the chorionic vesicles (ch.ves.).

Fig. 12. Section through body of uterus, Spec. B. $\quad \times$ about 12 .

Fig. 13. Trans. section through the allanto-chorion in the region of junction of umbilical cord with the inner wall of allantois, showing the cord (umb.c.), the allantoic cavity (all.cav.) crossed by two septa (sept.), the allantochorion (all.ch.) with its villi and two chorionic vesicles (ch.ves.), in the left one of which the opening $(o p$. $)$ is visible. $\times$ about 8.5 .

Fig. 14. Section similar to the preceding, more highly magnified to show the structure of the umbilical cord, allantois, and chorion. $\times$ about 12 .

Fig. 15. Section through the allanto-chorion and one of its villi, showing the allantoic entoderm (all.ent.), the connective tissue of the allanto-chorion (all.ch.) prolonged to form the axis of the villus (c.t.), in which are seen in section the smaller branches of the allantoic vessels. $\times$ about 48 .

Fig. 16. Section through a villous branch, to show the trophoblast $(t r$.$) , the under-$ lying capillary plexus (cap.), and the connective-tissue core (c.t.). Note the characteristic zone of the latter, below the capillaries (c.t'.). $x$ about 360. 


\section{$2 \mathrm{BHL}$ Biodiversity Heritage Library}

Hill, James Peter, Burne, R. H., and Pocock, R. I. 1922. "The Fœtal Membranes and Placentation of Chiromys madagascariensis." Proceedings of the Zoological Society of London 1922, 1145-1170.

https://doi.org/10.1111/j.1469-7998.1922.tb07098.x.

View This Item Online: https://www.biodiversitylibrary.org/item/100613

DOI: https://doi.org/10.1111/j.1469-7998.1922.tb07098.x

Permalink: https://www.biodiversitylibrary.org/partpdf/72069

\section{Holding Institution}

Smithsonian Libraries

\section{Sponsored by}

Biodiversity Heritage Library

\section{Copyright \& Reuse}

Copyright Status: Public domain. The BHL considers that this work is no longer under copyright protection.

This document was created from content at the Biodiversity Heritage Library, the world's largest open access digital library for biodiversity literature and archives. Visit BHL at https://www.biodiversitylibrary.org. 